\title{
EXAMINING THE DARK SIDE OF MOTIVATION ON LIFE SATISFACTION IN COLLEGE STUDENTS: DOES GRIT MATTER?
}

\author{
Elisa Huéscar Hernández', Juan Antonio Moreno-Murcia', Luís Cid²,3, \\ Diogo Monteiro ${ }^{3,4}$ and Filipe Rodrigues ${ }^{2,5}$ \\ ${ }^{1}$ Miguel Hernández University, Elche, Alicante (Spain); ${ }^{2}$ Sport Science \\ School of Rio Maior; ${ }^{3}$ Health and Human Development, Vila Real; ${ }^{4}$ ESECS- \\ Polytechnic of Leiria; ${ }^{5}$ Life Quality Research Center, Santarém (Portugal)
}

\begin{abstract}
Despite the fact that teachers can have an important effect on the regulation of student behavior, the existing scientific literature has hardly explored the simultaneous influence of personal traits and social factors to promote student well-being. This study examined the mediating role of amotivated behavior and the relationship with teacher controlling behaviors, grit, and satisfaction with life. A total of 474 college students (female= 135; male= 339) participated in the study. All participants completed a multi-section survey assessing the constructs under analysis. Results from the structural model analysis displayed acceptable fit and amotivation played a mediating role in the relationship between grit-perseverance and life satisfaction but not for gritpassion. These findings provide evidence regarding adequate teacher behavior and the importance of measuring student grit in the classroom setting. These findings provide new insights into the understanding of teacher motivational behaviors and student learning processes that influence student behavioral regulations and affective outcomes.

KEY WORDS: Self-determined motivation, perseverance, passion, well-being, students, motivation.
\end{abstract}

\section{Resumen}

A pesar de que los docentes pueden ejercer un efecto importante sobre la regulación del comportamiento de los estudiantes, la literatura científica existente ha explorado poco la influencia simultánea de los rasgos personales y los factores sociales para promover el bienestar de los estudiantes. Este estudio examinó el papel mediador de la desmotivación y las relaciones con el comportamiento controlador percibido del docente y la constancia del estudiante para mejorar la satisfacción con la vida. Participaron 474 estudiantes universitarios (339 hombres y 135 mujeres), que rellenaron los cuestionarios sobre las variables incluidas en el estudio. Los resultados del análisis del modelo de ecuaciones estructurales mostraron un ajuste adecuado, mostrando el papel mediador de la desmotivación en la relación entre la dimensión perseverancia de la constancia y la satisfacción

Correspondence: Juan Antonio Moreno Murcia, Miguel Hernández University, Sport Research Center, Avda. de la Universidad, s/n, 03202 Elche, Alicante (Spain).E-mail: j.moreno@umh.es 
con la vida, pero no lo hizo así la dimensión pasión. Los resultados aportan pruebas respecto a los comportamientos adecuados del docente y las medidas de la individualidad del estudiante en relación con la constancia a tener en cuenta para optimizar el escenario de aprendizaje.

PALABRAS CLAVE: Teoría de la autodeterminación, perseverancia, bienestar, estudiantes universitarios, motivación.

\section{Introduction}

From the self-determination theory perspective (Ryan \& Deci, 2017), teacher motivational styles have been conceptualized as the typical interpersonal behavior that students perceive in relationship to their motivation and academic consequences. There has been a recent consensus that two fundamentally different patterns of teacher motivational styles exist that reflect either autonomy support or control by the teacher. These orientations have been labeled as autonomy-supportive and controlling teaching orientations and are anticipated to result in different types of outcomes for students (Reeve, 2016). While the autonomy-supportive style has been linked to fundamentally adaptive outcomes that fall on the "brighter side" of the motivational spectrum (Cheon, Reeve, Lee, \& Lee, 2018), the controlling style works in a contrary way and is representative of a "darker side" that is less adaptive in terms of student motivation and achievement (Bartholomew, Ntoumanis, Ryan, Bosch, \& Thogersen-Ntoumani, 2011).

Autonomy-supportive practices have garnered greater research in the past. These need-supportive behaviors are conceptualized as one in which the teacher adopts an understanding tone and appreciates each student perspective (Huescar et al., 2020). This approach is generally anticipated to stimulate initiative and student willingness to receive feedback. Teacher behavior that is consistent with the autonomy-supportive approach has been related to student basic needs satisfaction as well as to autonomous forms of motivation that are linked to positive well-being (Cheon et al., 2018; Cheon, Reeve, \& Song, 2016; Ryan \& Deci, 2017).

Although there has been a myriad of studies on teacher supporting behaviors in several adaptive outcomes (Cid et al., 2019; Hagger et al., 2009), student perception of controlling teaching styles only recently been examined in detail (Bartholomew et al., 2018). Teacher controlling behaviors are traditionally associated with teacher communicating a tone of pressure and self-view of thinking (Reeve, 2016). Under these more controlling learning circumstances, the teacher communicates in a way that does not leave much of an opening chance for dialogue with the student. These behaviors frequently result in the suppression of student initiative and the teacher tendency to use language such as "you should" or "you must" which further suppresses student engagement (Zougkou, Weinstein, \& Paulmann, 2017) and can reduce student perceived control (Cheon et al., 2016). In addition, this pattern of academic involvement leads to maladaptive outcomes for the student in the forms of alienation and disconnection from the learning process and may even contribute to antisocial behaviors (Haerens, Aelterman, Vansteenkiste, Soenens, \& Van Petegem, 2015; Hein, Koka, 
\& Hagger, 2015). In accordance with the self-determination perspective, researchers have thus proposed that the teacher motivational style sets in motion a variety of consequences (Ryan \& Deci, 2017).

A separate line of educational research is concerned on understanding the dispositional characteristics of students whose own motivational processes contribute to adaptive outcomes, such as resilience (González, Balaguer, \& Castillo, 2019) and self-control (Duckworth \& Gross, 2014). Within this research area, student grit has been examined as a potentially important interpersonal form of influence that can contribute to successful academic outcomes (Bowman, Hill, Denson, \& Bronkema, 2015; Cedré, Tynan, \& Harms, 2017; Reed \& Jeremiah, 2017).

Grit has been defined as "trait-level perseverance and passion for long-term goals" (Duckworth \& Quinn, 2009, p. 168). Thus, grit is a personality disposition that reflects the amount of effort that individuals employ in the process of attempting to attain a valued objective that contributes to their personal development (Duckworth, 2016). As such, "gritty" students are those that invest a great deal of effort in remaining connected to their objectives and tend to stay focused on achieving goals that reflect their interests (Duckworth, Grant, Loew, Oettingen, \& Gollwitzer, 2011; Duckworth \& Gross, 2014; Schmidt, Fleckenstein, Retelsdorf, Eskreis-Winkler \& Möller, 2017). Grit comprises two dimensions that include perseverance (grit- perseverance) and passion (grit-passion). These personal facets have been associated as personally important contributors under adverse circumstances such as after experiencing performance failure or lack of improvement over time (Bowman, et al., 2015). In a recent meta-analysis conducted on grit, Cedré et al. (2017) found that perseverance was a stronger component of grit over time than was passion. The importance of the dimension of perseverance in grit is also supported by other studies that have highlighted the capacity of the perseverance component to explain positive changes in academic success (Clark \& Malecki, 2019). These findings underscore the importance of assessing grit dimensions in the educational setting where student motivational characteristics could have a major influence upon behavior and emotional outcomes and operate in interaction with teacher interpersonal behaviors (Reeve, 2016).

Researchers have found that grit is related to various psychological and mental health outcomes, including happiness, psychological well-being, and satisfaction with life (Salles, Cohen, \& Mueller, 2014; Vainio \& Daukantaite, 2016; Von Culin, Tsukayama, \& Duckworth, 2014;). It is likely that students who feel that they always employ focused effort will be able to reach their goals more easily and obtain higher levels of subjective well-being even though in adverse conditions. In a recent study involving university students, Akbag and Ümmet (2017) found that grit and needs satisfaction were significant predictors of subjective well-being. In a similar work, Singh and Duggal (2008) found undergraduate student grit to be positively related to positive affect, happiness, and satisfaction with life. All in all, satisfaction with life seems to be the most global of constructs related to the subjective well-being of the individual (Diener, Suh y Oishi, 1997; Huéscar \& 
Moreno-Murcia, 2017) and refers to the positive evaluation at both cognitive and emotional levels of relative life circumstances.

Until today, some studies have pointed out that the controlling style is presented as an "inhibitory style" of adaptive results for the student, but nevertheless there are still some questions to be answered. In this sense, although the recent work by Tilga et al. (2020) in physical education classes reports that this behavioral pattern should be minimized because it subtracts the potential beneficial effects of autonomy support on student quality motivation, a greater knowledge about what other variables intrinsic to the student participate in these effects acting as triggers together with the motivating style of the teacher. In this way, minimal research to date has been conducted with the purpose of examining how "gritty" students respond under adverse contextual learning influences, particularly those circumstances that are not supportive of student initiative. In line with the Reeve (2016) study, it would be anticipated that students perception of teacher-induced controlling behaviors would not contribute to more favorable types of self-regulated motivation, but rather is to back up a lack of interest or even amotivated behavior. It has also been argued that motivation exerts a mediating influence between grit and student academic outcomes (Von Culin et al., 2014). To date, we are not aware of research that has examined other adaptive outcomes (e.g., life satisfaction) in the relationship between controlling teaching behaviors and personal grit and that may strengthen the tendency toward amotivation in students.

With the intention of responding to this gap in current literature, the purpose of this study was to test a structural model based upon the core concepts of selfdetermination theory and grit, in which students perception of teacher controlling behaviors and student grit are considered to be predictors of satisfaction with life, through the mediating influence of amotivation. As such, it is hypothesized that i) perceived teacher controlling behaviors would be positively associated with amotivation; ii) perceived teacher controlling behaviors would be negatively associated with satisfaction with life; iii) grit-passion and grit-perseverance would be negatively associated with amotivation; iv) grit-passion and grit-perseverance would be positively associated with satisfaction with life; v) amotivation would play a mediating role between teacher controlling behaviors and satisfaction with life; and, vi) amotivation would play mediator role between grit-passion and gritperseverance and satisfaction with life.

\section{Method}

\section{Participants}

The sample comprised 474 college students (females= 135 , males $=339$ ), aged between 18 and 36 years old $(M=21.56, S D=2.64)$, who were in the second or third year of the bachelor's degree of sport sciences. This study had a crosssectional design and participants responded to a self-administered electronic survey. Participants included for analysis were selected based on two criteria: first, only those aged above or equal to 18 years were considered for analysis, and 
second, participants were considered for analyses if they completed the first course year. This criterion was considered as they had a more stable experience and perceptions of their teachers.

\section{Instruments}

a) Controlling Teaching Style Scale (Moreno-Murcia, Pintado, Huéscar, \& Marzo, 2018). This scale was employed to assess the extent to which students perceived teachers adopting a controlling teaching style in the classroom setting. The 12-items (one factor) measures overall student perception of controlling behaviors (e.g., "Provides few instructions and limited alternatives on how to complete the work"). Items were preceded by the stem "My teacher..." and responses were provided based on a 7-point Likert-type scale ranging from 1 ("totally disagree") to 7 ("totally agree") in a single global score. Students were asked to respond to this measure based on their perceptions of controlling behaviors considering an overall view of teachers they had the most often contact with during the last semester.

b) Short Grit Scale (SGS; Duckworth \& Quinn, 2009). The SGS was used to assess grit-passion (four items, e.g. "I often set a goal but later choose to pursue a different one") and grit-perseverance (four items, e.g. "Setbacks don't discourage $m e^{\prime \prime}$ ). Responses to the eight items were provided based on a 5point ranging from 1 ("strongly disagree") to 5 ("strongly agree"). Students were asked to respond to the grit scale based on their overall perceptions of their traits during classes. The SGS has provided acceptable psychometric proprieties in the past, with scores higher than the minimum accepted value of .70 (Duckworth, Peterson, Matthews, \& Kelly, 2007).

c) Academic Motivation Scale (AMS; Vallerand, Blais Brière, \& Pelletier, 1989), Spanish version by Nuñez, Martí-Albo, and Navarro (2005). The intrinsic motivation subscale of AMS is a dimension to measure student motivation during study. Specifically, four items were employed to assess amotivation (e.g. "I don't know, I don't understand what I am doing in the university") students experience in the classroom context. Items assessing amotivation were preceded by the stem "Why do you study?" and responses were provided based a Likert-type scale that ranges from 1 ("totally disagree") to 7 ("totally agree"). This measure has shown reliable results in previous research, with scores higher than the minimum accepted value of .70 (Nuñez, MartíAlbo, \& Navarro, 2005).

d) Life Satisfaction Scale (LSS; Vallerand, Blais, Briére, \& Pelletier, 1989). The LSS was used to assess students' perception of satisfaction with life. This scale comprises five items assessing satisfaction with life (e.g., "I am satisfied with my life") and participants answered to the items using a 7-point scale anchored from 1 ("totally disagree") to 7 ("totally agree"). Previous studies (Atienza, Balaguer, \& Garcia-Merita, 2003) have shown the LSS to be a robust measure and support the use of this scale in the classroom context, with scores higher than the minimum accepted value of .70. 


\section{Procedure}

Approval to conduct the research was obtained from the Internal Review Board (DPS.JMM.01.17) prior to data collection. Data collection procedures were conducted in accordance with the Helsinki Declaration and its later amendments. Afterwards, school boards were individually contacted, and objectives were explained. Potential participants signed informed consent prior to the data collection and protection of anonymity and confidentiality information was provided. The questionnaires were provided to the students through Google Docs Questionnaire platform. Students in each class responded to the questionnaires in the classroom setting, without the presence of their teacher. Questionnaires completion time were approximately 10 minutes.

\section{Data analysis}

Required sample size was calculated using the G*Power 3.1 (Faul, Erdfelder, Buchner, \& Lang, 2009) software. The following parameters were considered to calculate needed sample: effect size $\left(f^{2}=.01\right), \alpha=.05$; power (.95), and four predictors (i.e., teacher controlling behaviors, grit-passion, grit-perseverance, and amotivation). The results revealed that 191 participants would be the minimal sample size. Since our sample size was above minimum required $(n=474)$, we move forward on conducting several other statistic tests.

Descriptive statistical were calculated for all participants. Correlations were calculated considering all factors under analysis. The internal consistency of each instrument was also assessed through the Raykov formula (Raykov, 1997) considering coefficients $\geq .70$ as acceptable (Hair, Black, Babin, \& Anderson, 2014).

\section{CONFIRMATORY AND STRUCTURAL MODEL ANALYSIS}

A two-step maximum likelihood process for a structural model was performed using the robust maximum likelihood in Mplus 7.4 (Múthen \& Múthen, 2010). First, a measurement model was estimated by conducting a confirmatory factor analysis to verify the extent to which each item provided acceptable loading to its pre-specified variable. Additionally, the measurement model was examined considering traditional and incremental indexes. Average variance extracted (AVE) was estimated to evaluate convergent validity and scores above 0.50 were considered adequate. Discriminant validity was achieved when AVE of each construct had values above squared correlations between all factors of the model (Hair et al., 2019). If the model would provide adequate fit, then a structural model would be performed to test the research hypothesis.

The following traditional indexes were used to assess model fit, namely: CFI and $\mathrm{TLI}$ values $\geq .90$, RMSEA and SRMR values $\leq .08$. These values have been recommended by researchers (Byrne, 2010; Hair et al., 2014; Marsh, Hau, \& Wen, 2004) in conducting confirmatory and structural model analysis. Following several recommendations (Williams \& MacKinnon, 2008; Mackinnon, Lockwood, \& 
Williams, 2004) direct and indirect effects were considered significant if its $95 \%$ confidence interval would not include " 0 " (zero).

\section{Results}

\section{Preliminary analysis}

Descriptive statistics along with bivariate correlations for all analysis variables appear in Table 1. College students revealed mean scores of grit-perseverance and grit-passion above midpoint. Teacher controlling behaviors and amotivation were below midpoint and satisfaction with life displayed the highest mean compared to the other analysis variables. All variables conformed to a normal distribution, since skewness and kurtosis were contained within cutoffs. Significant correlations were observed as theoretically expected: a) teacher controlling behaviors showed a negative and significant correlation with passion, perseverance, and satisfaction with life; b) passion and grit displayed a negative and significant correlation with amotivation, but a positive and significant correlation with satisfaction with life; c) amotivation showed a negative and significant association with satisfaction with life.

\section{Table 1}

Descriptive statistics, composite reliability, average variance extracted, and correlations

\begin{tabular}{|c|c|c|c|c|c|c|c|c|c|c|c|}
\hline \multirow{2}{*}{ Variables } & \multirow{2}{*}{ M } & \multirow{2}{*}{$S D$} & \multirow{2}{*}{ S } & \multirow{2}{*}{ K } & \multirow{2}{*}{ CR } & \multirow{2}{*}{ AVE } & \multicolumn{5}{|c|}{ Correlation matrix } \\
\hline & & & & & & & 1 & 2 & 3 & 4 & 5 \\
\hline $\begin{array}{l}\text { 1. Teacher controlling } \\
\text { style }\end{array}$ & 2.67 & .70 & 21 & 33 & .74 & .60 & 1 & .19 & .03 & .10 & .03 \\
\hline 2. Passion & 2.99 & .82 & .32 & -.16 & .69 & .59 & $-.43 * *$ & 1 & .22 & .20 & .08 \\
\hline 3. Perseverance & 4.05 & 58 & -.51 & .48 & 72 & .62 & $-.17^{\star}$ & $.47^{\star *}$ & 1 & .13 & .19 \\
\hline 4. Amotivation & 1.66 & 1.01 & 1.94 & 5.09 & .85 & .77 & $.32 * *$ & $-.36 * *$ & $-.36 * *$ & 1 & 21 \\
\hline 5. Satisfaction with life & 4.69 & 1.20 & -.22 & -.31 & .85 & .73 & $-.17 \star$ & $.26 * *$ & $.44 * \star$ & $-.46^{* \star}$ & 1 \\
\hline
\end{tabular}

Note: $\mathrm{S}=$ skewness; $\mathrm{K}=$ kurtosis; $\mathrm{CR}=$ composite reliability; $\mathrm{AVE}=$ average variance extracted; below diagonal line $=$ correlations; above diagonal line $=$ squared correlations; ${ }^{*} p=.05 ;{ }^{* \star} p=.01$.

Looking at internal consistency, all latent variables had acceptable composite reliability coefficients. AVE scores displayed acceptable convergent validity, and discriminant validity was achieved since the squared correlations (see Table 1) were below AVE values.

\section{Confirmatory and structural model}

All measures were examined for construct validity before testing confirmatory and structural models with all variables under analysis. The psychometric proprieties of each measure displayed good fit as seen in Table 2. Thus, the measurement model with all variables under analysis was examined, which also displayed an acceptable fit. The structural model of teacher controlling behaviors and grit factors as predictors of amotivation, and in consequence amotivation as a predictor of satisfaction with life provided adequate fit to the data. 
Table 2

Model fit indexes

\begin{tabular}{|l|c|c|c|c|c|}
\hline \multicolumn{1}{|c|}{ Model } & $\chi^{2} / d f$ & CFI & TLI & SRMR & RMSEA $[90 \%$ CI] \\
\hline Controlling Teaching Style Scale & 2.57 & .95 & .93 & .04 & $.05[.05, .07]$ \\
\hline Short Grit Scale & 2.45 & .97 & .97 & .05 & $.04[.03, .05]$ \\
\hline Motivation in Education Scale & 1.99 & .97 & .95 & .03 & $.04[.03, .05]$ \\
\hline Life Satisfaction Scale & 1.34 & .99 & .97 & .06 & $.03[.02, .04]$ \\
\hline Measurement model & 1.87 & .96 & .92 & .06 & $.04[.03, .06]$ \\
\hline Structural model & 2.21 & .94 & .91 & .07 & $.05[.04, .06]$ \\
\hline
\end{tabular}

Note: $\chi^{2} / d f=$ adjusted qui-square test; $\mathrm{CFl}=$ comparative fit index; $T \mathrm{TL}=$ Tucker-Lewis index; SRMR= standardized root mean square residual; RMSEA = root mean squared error of approximation; $90 \% \mathrm{Cl}=$ $90 \%$ confidence interval of RSMEA.

Significant direct effects were found (see Figure 1) among predictor and outcome variables: a) teacher controlling behaviors showed a significant positive effect on amotivation; b) grit-perseverance, but not grit-passion, displayed a significant negative effect on amotivation; and c) amotivation negatively predicted satisfaction with life. Then, indirect effects were examined. Specifically, controlling teaching style had a significant negative indirect effect with satisfaction with life $(\beta=-.12, \mathrm{Cl}=-.25,-.02)$. Contrarily, grit-perseverance displayed a significant and positive indirect effect on satisfaction with life $(\beta=.22, \mathrm{Cl}=.01, .25)$. Grit-passion demonstrated a positive but nonsignificant indirect association with satisfaction with life $(\beta=.02, \mathrm{Cl}=-.03, .11)$. These results provide evidence that amotivation could play a mediating role in the relationship between grit-perseverance and satisfaction with life, but not between grit-passion. Amotivation also mediated the relationship between controlling style and satisfaction with life.

Figure 1

Results from the structural model

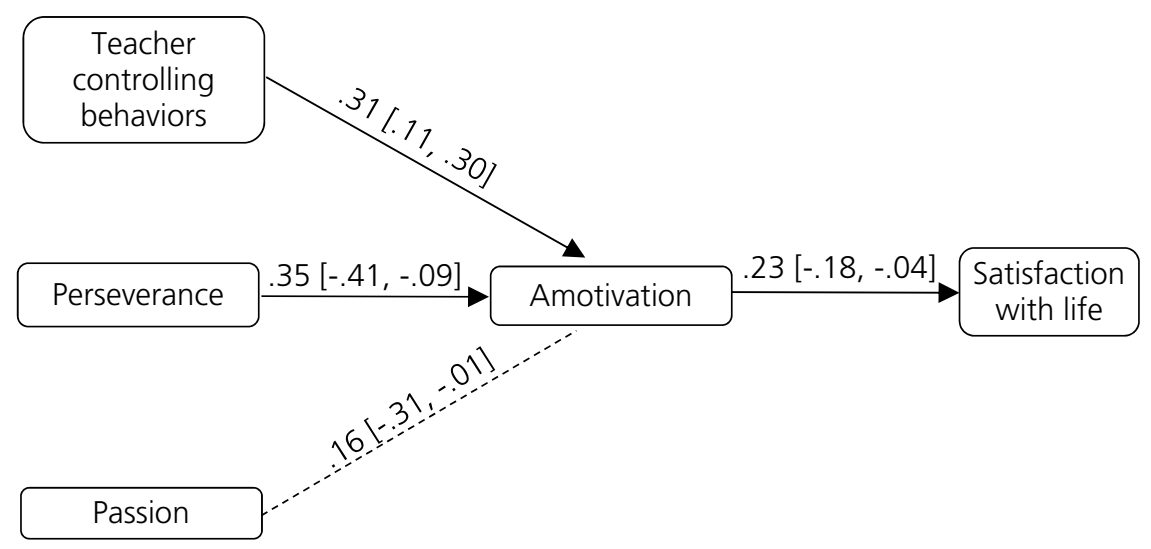

Notes: Square brackets= confidence interval at 95\%; thick lines= significant at $p>.05$. 


\section{Discussion}

Social and personal traits comprehension is crucial for success across academic achievement and overall subjective well-being. The purpose of this study was to examine relationships among teacher controlling behaviors, grit factors (i.e., passion and perseverance), amotivation, and student life satisfaction. Understanding the student individual differences that contribute to satisfaction with life is critical to addressing overall well-being. Some key findings emerged from this study. First, we found teacher controlling behaviors tended to predict positively amotivation as theoretically expected, however, it had a significant indirect effect on satisfaction with life. Second, passion did not display any significant effect on amotivation and neither on satisfaction with life. Third, perseverance was a negative predictor of amotivation, but had a positive and significant effect on satisfaction with life. This study provides new evidence that the grit dimensions of perseverance, but not passion, has an impact on student motivational regulation and positive affect.

Teacher controlling behaviors was positively related to amotivation which is consistent with Bartholomew and colleagues (2018). Teaching methods that limit student initiative and which are perceived as pressuring tend to reduce student self-determined motivation (e.g., amotivation). The hypotheses proposed with respect to the grit dimensions and amotivation were also supported. Specifically, grit-perseverance and grit-passion were each negatively related to amotivation which was a finding that was consistent with a previous investigation (Von Culin et al., 2014). Current evidence identified a positive relationship between grit dimensions and satisfaction with life in college students. A previous investigation with undergraduate students $(n=254)$ yielded the same positive relationship between grit dimensions and satisfaction with life (Singh \& Duggal, 2008). In our work, grit-perseverance demonstrated a stronger relationship than did gritpassion, a result that is also consistent with previous research with student populations (Cedré et al., 2017; Clark \& Malecki, 2019). In their study with adolescent students, Cedré et al. (2017) identified a stronger relationship between grit-perseverance and life satisfaction than between grit-passion and life satisfaction. In a sample of school-aged youth, Datu and colleagues (2016) found that grit-perseverance was significantly related to satisfaction with life whereas grit-passion was not. In sum, this pattern of findings highlights the significant correlation between grit-perseverance and overall well-being in students.

Although the main conclusions are consistent with our predictions, several interesting results emerged. Evidence was provided for the mediating role of amotivation in between teacher controlling behaviors and grit-perseverance (but not grit-passion) and satisfaction with life. Teachers who endorse in coercive and pressuring behaviors tend to promote less-self-determined behaviors, impacting negatively how students perceive their overall well-being. These findings are consistent with previous suggestions by self-determination theory researchers that people in key positions that are perceived as need-thwarting figures may stifle more controlled forms of motivation (Assor, Kaplan, Kanat-Maymon, \& Roth, 2005; Bartholomew et al., 2018; Moreno-Murcia, Huéscar \& Ruíz, 2018). It has 
been argued that controlling styles can provoke feelings of frustration among students in the educational setting and that negative consequences can emerge outside the classroom setting (De Meyer, Soenens, Aelterman, De Bourdeaudhuij, \& Haerens, 2016). However, the examination of the mediating role of amotivation between teacher controlling behaviors and satisfaction with life has not been consistently examined in previous research. It is worth to mention that the bivariate correlational relationship between teacher controlling behaviors and satisfaction with life was not significant and these findings is consistent with recent work by Moreno-Murcia and colleagues (2018). Evidences found that although these variables were not correlated, teacher controlling behaviors could have an indirect effect on overall satisfaction with life through the mediating role of behavior regulations. In accordance with past research, students perceiving teachers as having controlling behaviors could contribute to undesirable motivational and psychological outcomes in their overall life.

Further examination of the model revealed that higher levels of gritperseverance were associated with lower levels of amotivation which. Additionally, perseverance displayed a significant indirect effect student perception of satisfaction with life. This pattern of findings provides support previous literature in the relationships between grit and well-being (Clark \& Malecki, 2019), and grit and motivation in students (Von Culin et al., 2014). Current evidence suggest that perseverance is a crucial facet of grit which involves the ability to overcome failures and look at the bright side. Although controlling behaviors induced by teachers impact student overall perception of satisfaction with life, students with high levels of perseverance understand the value of persistence and hard work. Thus, even though students may perceive that their teachers are providing few instructions and limiting alternatives on how to complete several tasks, perseverant students are able to "override" and think positively that they can achieve positive outcomes. In line with some work that indicates that grit protects students against adversity (Hochanadel \& Finamore, 2015), it seems likely that persistence minimizes amotivation and contributes to life satisfaction. Thus, their overall wellbeing is determined by their perseverance towards their objectives and hard work.

Bailey and Phillips (2016) examined relationships among motivation, adaptive behaviors and life satisfaction in a sample of university students across various contexts and found bidirectional relationships between self-determined motivation and satisfaction with life across these contexts. These findings support assumptions (Vallerand, 2007) suggesting that not only motivation but also personal traits such as grit may contribute to the development of overall satisfaction with life. Diener (2000) has also proposed that individuals are more likely to experience happiness adaptive emotional outcomes when they can pursue challenging and interesting activities on their own.

Together, these findings indicate that social and personal factors have some form of effect on general satisfaction with life in college students (Baudin, Aluja, Rolland, \& Blach, 2011). This study was designed to test the conceptual foundations of self-determination theory and grit within the educational setting. Many of our results align with past theoretical literature (Deci \& Ryan, 1985) as 
well as conceptual and empirical works (Ryan \& Connell, 1989; Ryan \& Deci, 2000a; Zhao et al., 2018).

In sum, this work highlighted the role of grit-perseverance and student perception of teacher controlling behaviors upon general satisfaction with life through the mediating influence of amotivation in college students. We observed that higher levels of grit-perseverance and lower levels of perceived controlling behaviors were via amotivation predictive of higher levels of satisfaction with life.

Together, current findings indicate the importance of perseverance on student satisfaction with life. However, some limitations should be pointed out as suggestions for forthcoming research. First, only the "dark" side of teacher motivational behaviors was assessed. Given that our focal objective was to examine controlling behaviors and personal facets, it would have been informative to learn whether supportive behaviors would have a more predictive power on affective outcomes. As such, it would be interesting in the future to examine a dual process of motivation, assessing the bright and dark side of teacher interpersonal behaviors on students' motivation and overall well-being. In line with previous research (Chen et al., 2014; Rodrigues et al., 2019) supportive and thwarting behaviors induced by person in key positions can lead to differentiated outcomes. Second, gender-related and cultural factors should be examined in future studies to assess their potential influences upon student satisfaction with life. Our sample was mainly male students and Caucasians; thus, it was not possible to test the structural model between gender and ethnic cultures. We add to emphasize the need for broader testing of this model in other contexts. While these college students were enrolled in sport science courses, these students do not exactly mirror the student bodies of all courses. Moreover, because only student in the second and third year are included in this study, the validity of these findings for students in the first year or other related courses is untested. While this study analyzes a broad sample of college students than past work, forthcoming studies in other contexts are paramount to establish generalizability. Last, for the purpose of explaining these relationships through the framework provided by self-determination theory, it would be useful to measure basic psychological needs, and assess its influence between social factors (e.g., teacherinduced motivational behaviors) and dispositional facets (e.g., grit dimensions) on motivational and affective outcomes, and the teacher's own perception of his/her motivational style in class. Past literature has shown basic needs fulfillment to mediate the relationship between perceived social behaviors and behavioral regulations. (Cheon et al., 2016).

The findings from this study shed some light on the processes through which grit-perseverance benefits students in the educational context. The study also revealed that amotivation played a mediating role in the relationship between gritperseverance and life satisfaction and contributed to our understanding of how teacher controlling behaviors could be influential upon student motivational and affective outcomes in a manner that is consistent with expectations from the selfdetermination theory perspective. These evidences should be beneficial to the design of interventions that focus on enhancing student well-being and to 
augment teacher approaches intended to strengthen "gritty" students with concern for the attainment of beneficial long-term outcomes.

These findings have important implications for both theory and practice. Previous research using a "positive education" model has highlighted relationships between grit, personal growth, and well-being (Christensen \& Knezek, 2014) and has addressed the potential mediating role of autonomous motivation (Zhao et al., 2018). However, more research is needed to examine the interaction of grit dimensions and amotivation on how students are benefited by their hard work and effort towards achievement in the classroom setting.

\section{References}

Akbag, M., \& Ümmet, D. (2017). Predictive role of grit and basic psychological needs satisfaction on subjective well-being for young adults. Journal of Education and Practice, 8(26), 127-135.

Assor, A., Kaplan, H., Kanat-Maymon, Y., \& Roth, G. (2005). Directly controlling teacher behaviors as predictors of poor motivation and engagement in girls and boys: The role of anger and anxiety. Learning and Instruction, 15(5), 397-413.

Atienza, F. L., Balaguer, I., \& García-Merita, M. (2003). Satisfaction with Life Scale: Analysis of factorial invariance across sexes. Personality and Individual Differences, 35(6), 12551260. doi: 10.1016/S0191-8869(02)00332-X

Bailey, T., \& Phillips, L. (2016) The influence of motivation and adaptation on students' subjective well-being, meaning in life and academic performance, Higher Education Research \& Development, 35(2), 201-216, doi: 10.1080/07294360.2015.1087474

Baudin, N., Aluja, A., Rolland, J. P., \& Blanch, A. (2011). El papel de la personalidad en la satisfacción con la vida y el deporte [The role of personality in satisfaction with life and sport]. Behavioral Psychology/Psicología Conductual, 19(2), 333-345.

Bartholomew, K.J., Ntoumanis, N., Mouratidis, A., Katartzi, E., Thørgensen-Ntoumani, C., \& Vlachopoulos, S. (2018). Beware of your teaching style: A school-yearlong investigation of controlling teaching and student motivational experiences. Learning and Instruction, 53, 50-63.

Bartholomew, K., Ntoumanis, N., Ryan, R., Bosch, J., \& Thøgersen-Ntoumani, C. (2011). Self-determination theory and diminished functioning: The role of interpersonal control and psychological need thwarting. Personality and Social Psychology Bulletin, 37, 1459-1473.

Bowman, N., Hill, P., Denson, N., \& Bronkema, R. (2015). Keep on trucking or stay the course? Exploring grit dimensions as differential predictors of educational achievement, satisfaction, and intentions. Social Psychological and Personality Science, 6(6), 639-645.

Byrne, B. (2010). Structural equation modeling with AMOS. Basic concepts, applications, and programming ( $2^{\text {nd }}$ ed.). New York, NY: Taylor and Francis.

Cedré, M., Tynan, M., \& Harms, P. (2017). Much ado about grit: A meta-analytic synthesis of the grit literature. Journal of Personality and Social Psychology, 113(3), 492-511.

Chen, B., Vansteenkiste, M., Beyers, W., Boone, L., Deci, E. L., Van der Kaap-Deeder, J., Duriez, B., Lens, W., Matos, L., Mouratidis, A., Ryan, R. M., Sheldon, K. M., Soenens, B., Van Petegem, S., \& Verstuyf, J. (2015). Basic psychological need satisfaction, need frustration, and need strength across four cultures. Motivation and Emotion, 39, 216236. doi: 10.1007/s11031-014-9450-1 
Cheon, S., Reeve, J., Lee, Y., \& Lee, J. (2018). Why autonomy-supportive interventions work: Explaining the professional development of teachers' motivating style. Teaching and Teacher Education, 69, 43-51.

Cheon, S., Reeve, J., \& Song, Y. (2016). A teacher-focused intervention to decrease PE students' amotivation by increasing need satisfaction and decreasing need frustration. Journal of Sport and Exercise Psychology, 38, 217-235.

Christensen, R., \& Knezek, G. (2014). Comparative measures of grit, tenacity and perseverance. International Journal of Learning, Teaching and Educational Research, 8, 16-30.

Clark, N., \& Malecki, C. (2019). Academic Grit Scale: Psychometric properties and associations with achievement and life satisfaction. Journal of School Psychology, 72, 49-66. doi: 10.1016/j.jsp.2018.12.001

Datu, J., Valdez, J., \& King, R. (2016). Perseverance counts but consistency does not! Validating de Short Grit Scale in a collectivist setting. Current Psychology, 35, 121-130.

Deci, E., \& Ryan, R. (1985). The general causality orientations scale: Self-determination in personality. Journal of Research on Personality, 19, 109-134. doi: 10.1016/00926566(85)90023-6

De Meyer, J., Soenens, B., Aelterman, N., De Bourdeaudhuij, I., \& Haerens, L. (2016). The different faces of controlling teaching: Implications of a distinction between externally and internally controlling teaching for students' motivation in physical education. Physical Education and Sport Pedagogy, 21, 632-652. doi: 10.1080/17408989.2015.1112777

Diener, E. (2000). Subjective well-being: The science of happiness and a proposal for a national index. American Psychologist, 55, 34-43.

Diener, E., Suh, E., \& Oishi, S. (1997). Recent findings on subjective well-being. Indian Journal of Clinical Psychology, 24, 25-41.

Duckworth, A. (2016). Grit: The power of passion and perseverance. New York, NY: Simon and Schuster.

Duckworth, A., Grant, H., Loew, B., Oettingen, G., \& Gollwitzer, P. (2011). Self-regulation strategies improve self-discipline in adolescents: benefits of mental contrasting and implementation intentions. Educational Psychology, 31(1), 17-26, doi: $10.1080 / 01443410.2010 .506003$

Duckworth, A., \& Gross, J. (2014). Self-control and grit: Related but separable determinants of success. Current Directions in Psychological Science, 23, 319-325. doi: 10.1177/0963721414541462

Duckworth, A. L., Peterson, C., Matthews, M., \& Kelly, D. (2007). Grit: Perseverance and passion for long-term goals. Journal of Personality and Social Psychology, 92, 10871101. doi: 10.1037/0022-3514.92.6.1087

Duckworth, A., \& Quinn, P. (2009). Development and validation of the Short Grit Scale (GRIT-S). Journal of Personality Assessment, 91, 166-174. doi: $10.1080 / 00223890802634290$

Faul, F., Erdfelder, E., Buchner, A., \& Lang, A. (2009) Statistical power analyses using G*Power 3.1: Tests for correlation and regression analyses. Behavior Research Methods, 41,1149-1160. doi: 10.3758/BRM.41.4.1149

González, L., Balaguer, I., \& Castillo, I. (2019). Análisis del papel de la resiliencia y de las necesidades psicológicas básicas como antecedentes de las experiencias de diversión y aburrimiento en el deporte femenino [Analysis of the role of resilience and basic psychological needs as antecedents of experiences of fun and boredom in women's sport]. Revista de Psicodidáctica, 24(2), 131-137.

Haerens, L., Aelterman, N., Vansteenkiste, M., Soenens, B., \& Van Petegem, S. (2015). Do perceived autonomy-supportive and controlling teaching relate to physical education 
students' motivational experiences through unique pathways? Distinguishing between the bright and dark side of motivation. Psychology of Sport and Exercise, 16, 26-36. doi: 10.1016/j.psychsport.2014.08.013

Hochanadel, A., \& Finamore, D. (2015). Fixed and growth mindset in education and how grit helps students persist in the face of adversity. Journal of International Education Research, 11, 47-50.

Huéscar, E., \& Moreno-Murcia, J. A. (2017). Apoyo a la autonomía entre estudiantes, estrés percibido y miedo a la evaluación negativa: relaciones con la satisfacción con la vida. [Support for autonomy among students, perceived stress and fear of negative evaluation: relationships with life satisfaction]. Behavioral Psychology/Psicología Conductual, 25(3), 517-528.

Kline, R. (2011). Principles and practice of structural equation modeling ( $3^{\text {rd }}$ ed.). New York, NY: Guilford.

Haerens, L., Aelterman, N., Vansteenkiste, M., Soenens, B., \& Van Petegem, S. (2015). Do perceived autonomy-supportive and controlling teaching relate to physical education students' motivational experiences through unique pathways? Distinguishing between the bright and dark side of motivation. Psychology of Sport and Exercise, 16, 26-36. doi: 10.1016/j.psychsport.2014.08.013

Hagger, M., \& Chatzisarantis, N. (2016). Trans-contextual model of autonomous motivation in education: Conceptual and empirical issues and meta-analysis. Review of Educational Research, 86(2), 360-407.doi: 10.3102/0034654315585005

Hein, V., Koka, A., \& Hagger, M. (2015). Relationships between perceived teachers' controlling behavior, psychological need thwarting, anger and bullying behavior in high-school students. Journal of Adolescence, 42, 103-114.

Hair, J., Black, W., Babin, B., \& Anderson, R. (2014). Multivariate data analysis (7th ed.). New Jersey, NJ: Pearson Educational.

MacKinnon, D., Lockwood, C., \& Williams, J. (2004). Confidence limits for the indirect effect: Distribution of the product and resampling methods. Multivariate Behavioral Research, 39, 99-128.

Marsh, H., Hau, K., \& Wen, Z. (2004). In search of golden rules: Comment on hypothesis testing approaches to setting cutoff values for fit indexes and dangers in overgeneralizing $\mathrm{Hu}$ and Bentler's (1999) findings. Structural Equation Modeling: A Multidisciplinary Journal, 11(3), 320-341. doi:10.1207/s15328007sem1103_2

Moreno-Murcia, J. A., Huéscar, E., \& Ruíz, L. (2018). Perceptions of controlling teaching behaviors and the effects on the motivation and behavior of high school physical education students. International Journal of Environmental and Public Health, 15(10), 2228. doi: 10.3390/ijerph15102288

Moreno-Murcia, J. A., Pintado, R., Huéscar, E., \& Marzo, J. C. (2018). Estilo interpersonal controlador y percepción de competencia en educación superior [Controlling interpersonal style and perception of competence in higher education]. European Journal of Education and Psychology, 11(1), 33-45.

Nevitt, J., \& Hancock, G. (2001). Performance of bootstrapping approaches to model test statistics and parameter standard error estimation in structural equation modeling. Structural Equation Modeling, 8(3), 353-377.

Raykov, T. (1997). Estimation of composite reliability for congeneric measures. Applied Psychological Measurement, 21(2), 173-184.

Reed, L., \& Jeremiah, J. (2017). Student grit as an important ingredient for academic and personal success. Developments in Business Simulation and Experiential Learning, 44, 252-256. 
Reeve, J. (2016). Autonomy-supportive teaching: What it is, how to do it. In J. Wang, W. Liu, \& R. Ryan (Eds.), Motivation in educational research: Translating theory into classroom practice (pp. 129-152). New York, NY: Springer.

Ryan, R. M., \& Deci, E. L. (2000). Intrinsic and extrinsic motivations: Classic definitions and new directions. Contemporary Educational Psychology, 25, 54-67. doi: 10.1006/ceps. 1999.1020

Ryan, R., \& Deci, E. (2017). Self-determination theory: Basic psychological needs in motivation, development, and wellness. New York, NY: Guilford.

Salles, A., Cohen, G., \& Mueller, C. (2014). The relationship between grit and resident wellbeing. The American Journal of Surgery, 207(2), 251-254. doi: 10.1016/j.amjsurg.2013.09.006

Singh, K., \& Duggal, S. (2008). Positive and negative affect, and grit as predictors of happiness and life satisfaction. Journal of the Indian Academy of Applied Psychology, 34, 40-45.

Schmidt, F., Fleckenstein, J., Retelsdorf, J., Eskreis-Winkler, L., \& Möller, J. (2017). Measuring Grit. A German validation and a domain-specific approach to Grit. European Journal of Psychological Assessment, 35(3), 436-447. doi: 10.1027/1015-5759/a000407

Tilga, H., Kalajas-Tilga, H., Hein, V., Raudsepp, L. \& Koka, A. (2020). How teachers' controlling behaviour can ruin students' intrinsic motivation in a physical education lesson: Test of a conditional process model. International Journal of Sport Psychology, 51,81-99. doi: 10.7352/IJSP.2020.51.081

Vainio, M., \& Daukantaite, D. (2016). Grit and different aspects of wellbeing: Direct and indirect relationships via sense of coherence and authenticity. Journal of Happiness Studies, 17(5), 2119-2147. doi:10.1007/s10902-015-9688-7

Vallerand, R. (2007). Intrinsic and extrinsic motivation in sport and physical activity: A review and a look at the future. In G. Tenenbaum y E. Eklund (Eds.), Handbook of sport psychology (3 $3^{\text {rd }}$ ed., pp. 59-83). New York, NY: Wiley.

Vallerand, R., Blais, M., Brière, N., \& Pelletier, L. (1989). Construction et validation de l'échelle de motivation en éducation (EME) [Construction and validation of the Motivation toward Education Scale]. Canadian Journal of Behavioural Science/Revue Canadienne Des Sciences Du Comportement, 21, 323-349. doi: http://dx.doi.org/10.1037/h0079855

Von Culin, K., Tsukayama, E., \& Duckworth, A. (2014). Unpacking grit: Motivational correlates of perseverance and passion for long-term goals. The Journal of Positive Psychology, 9(4), 306-312. doi: 10.1080/17439760.2014.898320

Williams, J., \& Mackinnon, D. (2008). Resampling and distribution of the product methods for testing indirect effects in complex models. Structural Equation Modeling: A Multidisciplinary Journal, 15(1), 23-51. doi: 10.1080/10705510701758166

Zhao, Y., Niu, G., Hou, H., Zeng, G., Xu, L., Peng, K., \& Yu, F. (2018). From growth mindset to grit in Chinese schools: The mediating roles of learning motivations. Frontiers in Psychology, 9, 2007. doi: 10.3389/fpsyg.2018.02007

Zougkou, K., Weinstein, N., \& Paulmann, S. (2017). ERP correlates of motivating voices: Quality of motivation and time-course matters. Social Cognitive and Affective Neuroscience, 12, 1687-1700.

ReCEIVED: April 5, 2020

ACCEPTED: October 23, 2020 